\section{Non-thermal inactivation of Listeria spp. in a typical dry-fermented sausage: "Bergamasco" salami}

\author{
Erica Tirloni, ${ }^{1}$ Vanessa Di Pietro, ${ }^{2}$ \\ Giuseppe Rizzi, ${ }^{3}$ Francesco Pomilio, ${ }^{4}$ \\ Patrizia Cattaneo, ${ }^{1}$ \\ Cristian Bernardi, ${ }^{1}$ Simone Stella ${ }^{1}$
}

${ }^{1}$ Department of Health, Animal Science and Food Safety, University of Milan; ${ }^{2}$ Freelance, Bergamo; ${ }^{3}$ Fratelli Rizzi srl, Bergamo; ${ }^{4}$ Istituto Zooprofilattico Sperimentale dell'Abruzzo e del Molise "G. Caporale", Teramo, Italy

\begin{abstract}
Aim of the present study was the evaluation of the growth potential of Listeria spp. inoculated in the typical North Italian dry fermented sausage "Bergamasco" salami during its production. As it was necessary to carry out the challenge test in the production line of the industry, according to the guidelines of the European Reference Laboratory for Listeria monocytogenes, a non-pathogenic "surrogate" microorganism was used: for the inoculum, two strains of Listeria innocua (1 ATCC, 1 strain isolated from a similar substrate) were used. The inoculation of the samples occurred during grinding and mixing of the sausage mass, before the filling. To avoid cross-contamination, the control samples were produced before the contaminated ones. After the dripping, salamis were subjected to the normal production process (drying and maturation in five steps at specific temperatures and humidity rates). The inoculated products were subjected to the enumeration of Listeria spp. at T0 (day of inoculation) and at T4 (post-drying), and every 10 days during curing (T10, T20, T30, T40, T50, T60, T70, T80 and T90), as this salami is generally sold as whole piece with varying levels of curing (from T20 to T90). Since the product may be cut in half and vacuumpacked, at each of the times starting from T20, half salami was vacuum-packed and stored for 30 days at $12^{\circ} \mathrm{C}$, at the end of the which Listeria spp. enumeration was performed again. At all times and for each type of samples of each of the three batches, the enumeration of the natural microflora (Total Viable Count, lactic acid bacteria, Pseudomonas spp., Enterobacteriaceae) and the determination of water activity and $\mathrm{pH}$ were performed on control samples. The
\end{abstract}

product was characterized by a high concentration of microflora (8-8.5 Log UFC/g), consisting mainly of lactic acid bacteria, added to the mixture at the beginning of the production process. The $\mathrm{pH}$ showed a decrease over time, expected for this type of products, due to the development of lactic acid bacteria (final $\mathrm{pH}: 5.42-5.55$ ). The water activity reached values able to inhibit the development of Listeria spp. (final $\mathrm{a}_{\mathrm{w}}$ : 0.8260.863 ). Listeria counts in the tested batches of "Bergamasco" salami showed the absence of significant growth in the product with a reduction of loads if compared to $\mathrm{T} 0$, between -0.59 and $-1.04 \mathrm{Log}$ CFU/g. Even in the samples subjected to vacuum packaging and storage at $12^{\circ} \mathrm{C}$, the absence of significant increase of lactic acid bacteria in the product was highlighted with further decrease of bacterial loads (-0.70/-0.79 Log $\mathrm{CFU} / \mathrm{g}$ if compared to T20). Considering the worst case scenario (thus the batch with the highest growth potential), in the products stored in the curing room at $14-16^{\circ} \mathrm{C}$, at humidity of $80 \%$ and in the samples stored at $12^{\circ} \mathrm{C}$ and vacuum packaged, the threshold indicated by the EURL Lm guidelines $(+0.5$ $\log \mathrm{CFU} / \mathrm{g}$ ) for the growth of Listeria spp. was not reached, allowing to classify "Bergamasco" salami in the category 1.3 of the EC Reg. 2073/2005 as "Ready-to-eat food unable to support the growth of Listeria monocytogenes".

\section{Introduction}

The presence of Listeria monocytogenes (L. monocytogenes) in dry fermented sausages is currently one of the main concerns for meat industry. Dry fermented sausages are Ready-to-Eat (RTE) products where the presence of this pathogen represents a potential risk for consumers, especially for susceptible populations. In fact, invasive listeriosis mainly occurs in immunocompromised patients, elderly people, pregnant women, young, unborn or newborns. In particular, pregnant women experience mild symptoms followed by abortion, stillbirth, premature birth or newborns subjected to bacteraemia and meningitis (Jackson et al., 2010; Silk et al., 2012).

Although relatively rare, invasive listeriosis is characterized by high fatality (16.7\% in 2016) and hospitalization rates (97.7\% in 2016) and it is considered of major concern (EFSA-ECDC, 2017). Several studies reported the presence of $L$. monocytogenes in Italian sausages with prevalence from 9 to $45 \%$ (Cantoni et al., 1988; Barbuti et al., 1989; Cantoni, 1991; De Cesare et al., 2007; Meloni, 2015) and concentration generally below 1 Log $\mathrm{CFU} / \mathrm{g}$, but in some sporadic cases higher
Correspondence: Erica Tirloni, Department of Health, Animal Science and Food Safety, University of Milan, Via Celoria 10, 20133, Milan, Italy.

Tel.: +39.02 .50317855$

Fax: +39.02 .50317870$

E-mail: erica.tirloni@unimi.it

Key words: dry-fermented sausage; growth potential; Listeria; EURL Lm guidelines.

Contributions: the authors contributed equally.

Conflict of interests: the authors declare no conflict of interests.

Funding: none.

Received for publication: 14 February 2019. Accepted for publication: 7 May 2019.

This work is licensed under a Creative Commons Attribution-NonCommercial 4.0 International License (CC BY-NC 4.0).

(C) Copyright: the Author(s), 2019

Licensee PAGEPress, Italy

Italian Journal of Food Safety 2019; 8:8112

doi:10.4081/ijfs.2019.8112

than $3 \mathrm{Log}$ CFU/g (Thevenot et al., 2005; De Cesare et al., 2007; Martin et al., 2011; Meloni, 2015). Outbreaks and sporadic cases of listeriosis are mainly associated with RTE foods, that are expected to be eaten without any application of killing process before consumption (Farber and Peterkin, 1991; FAO-WHO, 2001; EFSAECDC, 2017). According to EFSA-ECDC (2017), L. monocytogenes is more prevalent in 'RTE fish' with $10.3 \%$ of positive samples $(1.7 \%$ above $100 \mathrm{CFU} / \mathrm{g})$ and in 'RTE meat' with $2.07 \%$ of positive samples (0.43\% above $100 \mathrm{CFU} / \mathrm{g})$. Moreover, during the time period 2008-2015, non-compliance at processing ranged from $0.9 \%$ to $6.8 \%$ for RTE products of meat origin other than fermented sausages, and from $0 \%$ to $0.6 \%$ for RTE products of meat origin and fermented sausages. Contamination of dryfermented sausages is mainly due to the presence of L. monocytogenes in raw materials (e.g. pork) (Thevenot et al., 2005), but its survival in the final product is frequent (Tompkin, 2002). The presence of the pathogen in the final products due to a contamination during slicing and packaging has been reported by Martin et al. (2011); theses authors detected relatively high prevalence rates of L. monocytogenes in the equipment $(11.8 \%)$, raw materials $(28.9 \%)$, and final products $(15.8 \%)$, in small-scale Spanish factories producing traditional fermented sausages. 
During fermentation and drying of sausages, L. monocytogenes is reported to decrease due to the combined action of several hurdles such as the reduction of water activity $\left(\mathrm{a}_{\mathrm{w}}\right)$, and the competing effect of lactic acid microflora added to the mass (Bunčić et al., 1991). Mataragas et al. (2015) reported a linear decrease of $L$. monocytogenes in artificially contaminated Italian salami ("Cacciatore" and "Felino"), highlighting how $\mathrm{pH}$ and $\mathrm{a}_{\mathrm{w}}$ resulted to be crucial parameters during fermentation. Also, Drosinos et al. (2006) reported a concentration reduction of 3-4 Log CFU/g after 28 days of drying in a Serbian fermented sausage.

The compliance with the limit of 100 CFU/g throughout the shelf-life of RTE products, is in charge to food business operators (Reg. EU 2073/2005). According to the European Reference Laboratory for Listeria monocytogenes (EURL Lm), the growth potential (d), as the difference between the L. monocytogenes concentration found at the end and the at the beginning of the shelf-life in Log CFU/g is one of the options to classify the product as able or unable to support the growth of L. monocytogenes (ANSES, 2014).

In particular, when $\mathrm{d}$ is $>0.5 \mathrm{Log}$ $\mathrm{CFU} / \mathrm{g}$, food is classified as "Ready-to-eat food able to support the growth of $L$. monocytogenes other than those intended for infants and for special medical purposes" (category 1.2), while if $\delta$ is $\leq 0.5 \mathrm{Log}$ $\mathrm{CFU} / \mathrm{g}$, food is classified as "Ready-to-eat food unable to support the growth of $L$. monocytogenes other than those intended for infants and for special medical purposes" (category 1.3).

Aim of the present study was to evaluate the growth potential of $L$. monocytogenes in "Bergamasco" salami in accordance with EURL Lm guidelines to satisfy the need of the food safety criteria for L. monocytogenes as reported in EU legislation.

\section{Materials and Methods}

\section{Ingredients}

The trial was conducted on "Bergamasco" salami produced starting from swine meat and fat, $\mathrm{NaCl}(2-2.5 \%$ was added to the mass), spices, sodium nitrite, potassium nitrate. A mixture of starter cultures was added to the salami mass before the filling, and was composed by Staphylococcus carnosus, Pedioccocus acidilactici and Lactobacillus plantarum. The manufacturing company produced different sizes of the product, made with the same salami mass, thus the largest size (1 $\mathrm{kg}$ ) was chosen as worst-case scenario, as it is characterized by a slower drying if compared to a salami of a smaller size.

\section{Production process}

The production process includes the following phases: reception of the cut meat and fat, storage in refrigerated rooms at $1-2^{\circ} \mathrm{C}$, grinding and mixing of the ingredients, addition of starter cultures and other ingredients, filling, dripping for 2-5 hours at a temperature of $28 \pm 2^{\circ} \mathrm{C}$ (free relative humidity), drying and curing divided in 5 phases as follows: first phase for $12 \pm 2$ hours at a temperature of $16 \pm 2{ }^{\circ} \mathrm{C}$ and relative humidity of 60 $65 \%$; second phase for 24 hours at a temperature of $18 \pm 2{ }^{\circ} \mathrm{C}$ and relative humidity of 65 $70 \%$; third phase for 24 hours at a temperature of $20 \pm 2^{\circ} \mathrm{C}$ and relative humidity of $75 \%$, fourth phase for 24 hours at a temperature of $18 \pm 2^{\circ} \mathrm{C}$ and relative humidity of $75 \%$ and fifth phase that lasts up to the sale of the product, at a temperature of $14-16^{\circ} \mathrm{C}$ and relative humidity of $78-80 \%$.

The product is sold as whole piece, starting from T20 (calculated from the day of production) to T80 days of aging. During sale, the product could also be cut in two halves and vacuum-packed, with an additional shelf life of 30 days.

\section{Experimental protocol}

The protocol was developed following the indications of the EURL Lm technical guidance document for conducting shelf-life studies on Listeria monocytogenes in readyto-eat foods (ANSES, 2014).

\section{Number of batches}

The tested product has a certain variability especially regarding the raw ingredients (fresh pork); the availability of historical data on the characteristics of the product was limited, thus the challenge test was carried out on three batches of product.

\section{Choice of Listeria strains for the test}

As indicated in the EURL Lm guidelines, as it was necessary to conduct a challenge test directly at the production plant, a non-pathogenic "surrogate" microorganism, replacing L. monocytogenes, was used. The more similar candidate, from a metabolic and ecological point of view, was Listeria innocua: two strains were selected: L. innocua ATCC 33090 and a L. innocua strain previously isolated from a salami substrate.

\section{Evaluation of growth potential \\ of L. innocua in broth}

In order to determine whether the selected strains had a growth capacity comparable to L. monocytogenes, the two strains of L. innocua were compared to two strains of $L$. monocytogenes belonging to the panel of strains provided by the
National Laboratory of Reference for $L$. monocytogenes of the Istituto Zooprofilattico Sperimentale dell' Abruzzo e del Molise (NRL Lm). These strains, identified as 12MOB045LM and 12MOB085LM, were the most suitable for the conduction of challenge tests on meat products, for their excellent growth rates under conditions of low temperature, acidic $\mathrm{pH}$ or low water activity (ANSES, 2013).

The four strains ( 2 L. innocua and $2 L$. monocytogenes), kept frozen at $-80^{\circ} \mathrm{C}$ in Microbank Cryogenic vials (Pro-Lab Diagnostics U.K., Merseyside, UK), were grown in TSB (Tryptone Soy Broth, Biogenetics, Ponte San Nicolò, Italy) at $37^{\circ} \mathrm{C}$ in order to reach the same growth phase; then they were subjected to enumeration by microscope and diluted in order to obtain the same starting concentration ( $2 \mathrm{Log} \mathrm{CFU} / \mathrm{g})$. Each strain was then inoculated in duplicate in the following broths: TSB, TSB at pH 5.5 (adjusted with $\mathrm{HCl}$ ), frequent $\mathrm{pH}$ value found in salami, and TSB with $3 \% \mathrm{NaCl}$ in order to mimic the $\mathrm{NaCl}$ concentration of the salami mass. The broths were incubated at the following temperatures: $37^{\circ} \mathrm{C}$ (only the TSB broth, to verify the growth under optimal conditions), $20^{\circ} \mathrm{C}$ and $12^{\circ} \mathrm{C}$. For each sample, optical density (OD) at $540 \mathrm{~nm}$ (6320D spectrophotometer, Jenway, Staffordshire, UK) was determined at T0 (immediately after inoculation) and after 24 $\mathrm{h}$ and $48 \mathrm{~h}$ of incubation.

\section{Preparation of the inoculum and inoculation procedure}

L. innocua strains were subcultured in TSB broth at $37^{\circ} \mathrm{C}$ for $18 \mathrm{~h}$, in order to obtain strains at the early stationary growth phase. Then each strain was subcultured in a suspension obtained by homogenizing TSB broth with salami mass (in a 1:1 ratio), in order to pre-adapt the microorganisms to the substrate conditions. The suspensions were then incubated at $10-12^{\circ} \mathrm{C}$ for 3 days. Each of the bacterial suspensions was then enumerated (microscopic method) and diluted with sterile physiologic saline solution $(\mathrm{NaCl} 0.85 \%)$ in order to obtain the same concentration (4 Log CFU/ml); then, the two suspensions were mixed in equal quantity. The mixed suspension used for inoculation was subjected to microbial counts on Palcam agar (Biogenetics).

The inoculation of the samples was done during mixing of the salami mass, before the filling. The inoculum volume was $100 \mathrm{ml}$. This volume was adapted to the weight of the salami mass $(10 \mathrm{~kg}$ for each batch), in order to avoid a change in the substrate conditions $(1 \%$ of the total weight of the sample). The control samples were added with the same amount of sterile physiologic saline solution, in order to mimic the 
bacterial inoculum. In order to avoid crosscontamination, the control samples were produced and filled before those artificially contaminated. The contaminated and control salami were kept at the production site for the whole duration of the trial, in order to apply the usual drying and ageing conditions. Samples were analyzed at T0 (salami mass was sampled after inoculation and mixing), at T4 (after drying), and every 10 days when the product was ready for sale, starting from the $20^{\text {th }}$ day from the production (T20) and until the $90^{\text {th }}$ day (T90); the product is generally sold with a curing period of no more than 70-80 days. As there is the possibility that the salami, during the retail phase, could be cut in two halves and vacuum-packed, for the samples of each batch from T20, half salami was vacuumpacked and stored for a period of 30 days. These sampling units were then stored at $12 \pm 1{ }^{\circ} \mathrm{C}$ (thermal abuse condition intended to mimic retail and domestic storage).

\section{Determination of the absence} of Listeria spp. in control samples

To verify the absence of Listeria spp. in control samples, 3 non-inoculated sampling units of each batch were sampled in deep immediately after filling and subjected to detection of Listeria spp. In particular, $25 \mathrm{~g}$ of sample were diluted with $225 \mathrm{ml}$ of Half Fraser broth, incubated at $37^{\circ} \mathrm{C}$ for $24-48$ hours; afterwards a loop of the broth was streaked onto Palcam agar, and incubated at $37^{\circ} \mathrm{C}$ for 48 hours.

\section{Challenge tests analyses}

Inoculated samples were subjected to the enumeration of Listeria spp. in triplicate by diluting $1: 5$ the sample (10-15 g) in peptone saline solution $(8.5 \mathrm{~g} / \mathrm{L} \mathrm{NaCl}, 1 \mathrm{~g} / \mathrm{L}$ of peptone) and spreading on Palcam agar, incubated at $37^{\circ} \mathrm{C}$ for $48 \mathrm{~h}$. Sampling times were T0, T4, T20, T30, T40, T50, T60, T70, T80 and T90. For vacuum packed salami, sampling times were $\mathrm{T} 20+30, \mathrm{~T} 30+30$, $\mathrm{T} 40+30, \mathrm{~T} 50+30, \quad \mathrm{~T} 60+30, \mathrm{~T} 70+30$, $\mathrm{T} 80+30$ and $\mathrm{T} 90+30$.
Control samples were tested at the same time for the enumeration of Total bacterial mesophilic aerobic count (TVC-ISO 48332: 2013), Pseudomonas spp. (ISO 13720: 2010), Enterobacteriaceae (ISO 215282:2004), lactic acid bacteria (ISO 15214:1998), $\mathrm{pH}$ (by homogenization and dilution 1:5 with distilled water) and aw determination.

\section{Calculation of growth potential}

Results obtained from the enumeration of Listeria spp. have been transformed into Log CFU/g, and used to calculate the trend of the concentration in contaminated samples. According to the guidelines of the EURL Lm, the growth potential $(\delta)$ of $L$. monocytogenes in a food product is the difference between the logarithmic medians of the counts detected, respectively, at the end and at the beginning of the challenge test. Food is considered able to support L. monocytogenes growth when the $\delta$ value is greater than 0.5 . The growth potential was calculated for each lot, using median values. Once the values were calculated for each of the 3 batches analysed, the highest $\delta$ value was chosen.

\section{Results}

\section{Comparison between the growth}

of $L$. innocua strains and

\section{L. monocytogenes reference strains}

L. innocua strains used for the test showed growth rates similar to those reported for L. monocytogenes reference strains; the mean optical density values measured in inoculated broths are shown in Table 1 . The data measured at $12^{\circ} \mathrm{C}$ did not show any increase in optical density in $48 \mathrm{~h}$, and were not therefore reported in the table.

\section{Determination of the absence of Listeria spp. and enumeration of microflora in control samples}

The presence of Listeria spp. was never detected in control samples from the three batches analysed at $\mathrm{T} 0$. The results of the microbiological and chemical-physical analyses of batches 1,2 and 3 are reported in Tables 2, 3 and 4, respectively.

As reported in the tables, the TVC of salami ranged from 5.55 to $8.97 \mathrm{Log}$ $\mathrm{CFU} / \mathrm{g}$, and it was typical for this product, being substantially constituted by lactic acid bacteria coming from the addition of starter cultures and developed in the first production phases.

The concentration of Pseudomonas spp. ranged between 3,65 and 3,90 Log CFU/g at $\mathrm{T} 0$, then decreased, as a result of drying and acidification of salami; from T30-T40, these microorganisms were not further detected. Also, Enterobacteriaceae, whether naturally present in fresh pork, were almost constantly below 2 Log CFU/g. These values indicated a good hygiene of the meat used. The vacuum packaging of salami did not cause significant changes in the bacterial microflora.

The $\mathrm{pH}$ of the analysed salami showed a typical trend: starting from an initial value of 5.71-5.72 typical of fresh meat, an initial decline was observed in the early stages, due to the fast growth of added LAB. Then a gradual increase was observed, to 5.42-5.55, due to the normal proteolytic reactions occurred during the maturation of the product.

The same trend was observed in the vacuum packaged samples, where curing phenomena have led to a slight increase of the $\mathrm{pH}$, reaching values similar to those found in the unpackaged samples and stored for the same period.

The $\mathrm{pH}$ values observed during the trial are not sufficient to explain the absence of growth of Listeria spp. in all the batches. The $\mathrm{a}_{\mathrm{w}}$, was 0.950-0.954 at T0, then decreased during the drying and the first part of the curing: at T20, when the product could be sold, it reached a median value of 0.920 (0.919-0.940), limit of growth for $L$. monocytogenes, if considered as a single factor. In the following steps the aw steadily

Table 1. Optical density values detected in inoculated samples (reading against blank broth, expressed as difference from the value at inoculation).

\begin{tabular}{|c|c|c|c|c|c|}
\hline \multicolumn{2}{|c|}{ Condition of storage } & $\begin{array}{l}\text { L. innocua } \\
\text { ATCC } 33090\end{array}$ & $\begin{array}{c}\text { L. innocua } \\
\text { (salami substrate) }\end{array}$ & $\begin{array}{l}\text { L. monocytogenes } \\
\text { 12M0B045LM }\end{array}$ & $\begin{array}{l}\text { L. monocytogenes } \\
\text { 12MOB085LM }\end{array}$ \\
\hline $37^{\circ} \mathrm{C}$ & $\begin{array}{l}24 \mathrm{~h} \\
48 \mathrm{~h}\end{array}$ & $\begin{array}{l}1.429 \\
0.972\end{array}$ & $\begin{array}{l}1.395 \\
0.994\end{array}$ & $\begin{array}{l}1.155 \\
0.417\end{array}$ & $\begin{array}{l}1.185 \\
0.614\end{array}$ \\
\hline $20^{\circ} \mathrm{C}$ & $\begin{array}{l}24 \mathrm{~h} \\
48 \mathrm{~h}\end{array}$ & $\begin{array}{l}0.064 \\
1.364\end{array}$ & $\begin{array}{l}0.169 \\
1.446\end{array}$ & $\begin{array}{l}0.231 \\
1.333\end{array}$ & $\begin{array}{l}0.266 \\
1.304\end{array}$ \\
\hline $20^{\circ} \mathrm{C}, \mathrm{pH} 5.5$ & $\begin{array}{l}24 \mathrm{~h} \\
48 \mathrm{~h}\end{array}$ & $\begin{array}{c}-0.003 \\
0.816\end{array}$ & $\begin{array}{l}0.045 \\
0.928\end{array}$ & $\begin{array}{l}0.063 \\
0.782\end{array}$ & $\begin{array}{l}0.053 \\
1.059\end{array}$ \\
\hline $20^{\circ} \mathrm{C}, 3 \% \mathrm{NaCl}$ & $\begin{array}{l}24 \mathrm{~h} \\
48 \mathrm{~h}\end{array}$ & $\begin{array}{l}0.015 \\
1.308\end{array}$ & $\begin{array}{l}0.026 \\
1.488\end{array}$ & $\begin{array}{c}0.00 \\
1.301\end{array}$ & $\begin{array}{c}0.04 \\
1.262\end{array}$ \\
\hline
\end{tabular}


Table 2. Microbiological and chemical-physical characterization of control samples of batch 1 .

\begin{tabular}{|c|c|c|c|c|c|c|c|c|c|c|}
\hline Parameter & $\mathrm{T0}$ & T4 & $\mathrm{T} 20$ & T30 & $\mathrm{T} 40$ & T50 & $\mathrm{T} 60$ & $\mathrm{~T} 70$ & $\mathrm{~T} 80$ & T90 \\
\hline TVC* & 7.00 & 7.95 & 8.53 & 8.65 & 8.32 & 8.52 & 8.23 & 8.46 & 8.38 & 8.56 \\
\hline Pseudomonas spp.* & 3.65 & 3.26 & 2.48 & $<2.00$ & $<2.00$ & $<2.00$ & $<2.00$ & $<2.00$ & $<2.00$ & $<2.00$ \\
\hline Enterobacteriaceae* & $<2.00$ & $<2.00$ & $<2.00$ & $<2.00$ & $<2.00$ & $<2.00$ & $<2.00$ & $<2.00$ & $<2.00$ & $<2.00$ \\
\hline LAB* & 5.30 & 8.11 & 8.57 & 8.56 & 8.36 & 8.53 & 8.34 & 8.57 & 8.51 & 8.38 \\
\hline $\mathrm{pH}$ & 5.72 & 5.27 & 5.24 & 5.31 & 5.32 & 5.36 & 5.38 & 5.38 & 5.40 & 5.42 \\
\hline \multirow[t]{2}{*}{ aw } & 0.954 & 0.931 & 0.920 & 0.909 & 0.890 & 0.881 & 0.856 & 0.853 & 0.832 & 0.828 \\
\hline & & & $\mathrm{T} 20+30$ & $\mathrm{~T} 30+30$ & $\mathrm{~T} 40+30$ & $\mathrm{~T} 50+30$ & $\mathrm{~T} 60+30$ & $\mathrm{~T} 70+30$ & $\mathrm{~T} 80+30$ & $\mathrm{~T} 90+30$ \\
\hline TVC* & - & - & 8.41 & 8.30 & 8.23 & 8.19 & 8.36 & 8.04 & 8.30 & 7.84 \\
\hline Pseudomonas spp.* & - & - & 3.65 & 3.26 & $<2.00$ & $<2.00$ & $<2.00$ & $<2.00$ & $<2.00$ & $<2.00$ \\
\hline Enterobacteriaceae* & - & - & $<2.00$ & $<2.00$ & $<2.00$ & $<2.00$ & $<2.00$ & $<2.00$ & $<2.00$ & $<2.00$ \\
\hline LAB* & - & - & 8.56 & 8.28 & 8.54 & 8.37 & 8.33 & 8.21 & 8.36 & 8.04 \\
\hline $\mathrm{pH}$ & - & - & 5.35 & 5.36 & 5.40 & 5.48 & 5.53 & 5.56 & 5.56 & 5.51 \\
\hline aw & - & - & 0.914 & 0.904 & 0.888 & 0.871 & 0.859 & 0.845 & 0.844 & 0.826 \\
\hline
\end{tabular}

*TVC, Pseudomonas spp., Enterobacteriaceae and LAB are expressed as Log CFU/g.

Table 3. Microbiological and chemical-physical characterization of control samples of batch 2 .

\begin{tabular}{|c|c|c|c|c|c|c|c|c|c|c|}
\hline Parameter & 10 & $\mathrm{~T} 4$ & $\mathrm{~T} 20$ & $\mathrm{~T} 30$ & $\mathrm{~T} 40$ & 750 & $\mathrm{~T} 60$ & $\mathrm{~T} 70$ & T80 & T90 \\
\hline TVC* & 5.85 & 8.30 & 8.23 & 8.04 & 7.99 & 8.56 & 7.95 & 8.18 & 8.09 & 8.00 \\
\hline Pseudomonas spp.* & 3.83 & 3.41 & 2.85 & $<2.00$ & $<2.00$ & $<2.00$ & $<2.00$ & $<2.00$ & $<2.00$ & $<2.00$ \\
\hline Enterobacteriaceae* & $<2.00$ & $<2.00$ & $<2.00$ & $<2.00$ & $<2.00$ & $<2.00$ & $<2.00$ & $<2.00$ & $<2.00$ & $<2.00$ \\
\hline $\mathrm{LAB}^{*}$ & 5.17 & 8.48 & 8.40 & 8.36 & 8.26 & 8.60 & 7.95 & 8.30 & 8.27 & 8.18 \\
\hline $\mathrm{pH}$ & 5.71 & 5.26 & 5.28 & 5.34 & 5.40 & 5.38 & 5.54 & 5.53 & 5.47 & 5.46 \\
\hline \multirow[t]{2}{*}{ aw } & 0.950 & 0.943 & 0.919 & 0.923 & 0.898 & 0.900 & 0.877 & 0.881 & 0.864 & 0.845 \\
\hline & & & $\mathrm{T} 20+30$ & $\mathrm{~T} 30+30$ & $\mathrm{~T} 40+30$ & $\mathrm{~T} 50+30$ & $\mathrm{~T} 60+30$ & $\mathrm{~T} 70+30$ & $\mathrm{~T} 80+30$ & $\mathrm{~T} 90+30$ \\
\hline TVC* & - & - & 8.30 & 8.30 & 7.99 & 8.78 & 7.48 & 8.00 & 8.26 & 7.51 \\
\hline Pseudomonas spp.* & - & - & $<2.00$ & $<2.00$ & $<2.00$ & $<2.00$ & $<2.00$ & $<2.00$ & $<2.00$ & $<2.00$ \\
\hline Enterobacteriaceae* & - & - & $<2.00$ & $<2.00$ & $<2.00$ & $<2.00$ & $<2.00$ & $<2.00$ & $<2.00$ & $<2.00$ \\
\hline LAB* & - & - & 8.18 & 7.85 & 8.01 & 8.29 & 8.02 & 7.89 & 8.24 & 7.66 \\
\hline $\mathrm{pH}$ & - & - & 5.42 & 5.42 & 5.47 & 5.47 & 5.54 & 5.61 & 5.62 & 5.55 \\
\hline aw & - & - & 0.931 & 0.924 & 0.916 & 0.916 & 0.894 & 0.861 & 0.873 & 0.831 \\
\hline
\end{tabular}

${ }^{*} \mathrm{TVC}$, Pseudomonas spp., Enterobacteriaceae and LAB are expressed as Log CFU/g.

Table 4. Microbiological and chemical-physical characterization of control samples of batch 3.

\begin{tabular}{|c|c|c|c|c|c|c|c|c|c|c|}
\hline Parameter & TO & $\mathrm{T} 4$ & T20 & T30 & T40 & T50 & T60 & T70 & T80 & T90 \\
\hline TVC* & 5.55 & 8.00 & 8.23 & 8.28 & 8.25 & 7.85 & 8.20 & 8.54 & 7.63 & 8.97 \\
\hline Pseudomonas spp.* & 3.90 & 3.20 & 2.85 & 2.00 & $<2.00$ & 2.30 & $<2.00$ & $<2.00$ & $<2.00$ & $<2.00$ \\
\hline Enterobacteriaceae* & $<2.00$ & 2.90 & $<2.00$ & 2.30 & $<2.00$ & $<2.00$ & $<2.00$ & $<2.00$ & $<2.00$ & $<2.00$ \\
\hline $\mathrm{LAB}^{*}$ & 5.12 & 8.70 & 8.23 & 8.48 & 8.32 & 8.41 & 8.32 & 8.60 & 8.04 & 8.13 \\
\hline $\mathrm{pH}$ & 5.72 & 5.2 & 5.39 & 5.41 & 5.44 & 5.48 & 5.56 & 5.56 & 5.55 & 5.54 \\
\hline \multirow[t]{2}{*}{ aw } & 0.951 & 0.950 & 0.940 & 0.903 & 0.912 & 0.904 & 0.882 & 0.850 & 0.842 & 0.863 \\
\hline & & & $\mathrm{T} 20+30$ & $\mathrm{~T} 30+30$ & $\mathrm{~T} 40+30$ & $\mathrm{~T} 50+30$ & $\mathrm{~T} 60+30$ & $\mathrm{~T} 70+30$ & $\mathrm{~T} 80+30$ & $\mathrm{~T} 90+30$ \\
\hline TVC* & - & - & 8.11 & 8.00 & 7.70 & 8.03 & 8.15 & 8.23 & 8.00 & 7.90 \\
\hline Pseudomonas spp.* & - & - & $<2.00$ & $<2.00$ & $<2.00$ & $<2.00$ & $<2.00$ & $<2.00$ & $<2.00$ & $<2.00$ \\
\hline Enterobacteriaceae* & - & - & $<2.00$ & $<2.00$ & $<2.00$ & $<2.00$ & $<2.00$ & $<2.00$ & $<2.00$ & $<2.00$ \\
\hline LAB* & - & - & 8.38 & 8.11 & 7.82 & 8.18 & 8.24 & 8.30 & 7.81 & 7.82 \\
\hline $\mathrm{pH}$ & - & - & 5.44 & 5.51 & 5.57 & 5.53 & 5.65 & 5.58 & 5.57 & 5.55 \\
\hline aw & - & - & 0.935 & 0.927 & 0.910 & 0.897 & 0.873 & 0.871 & 0.864 & 0.852 \\
\hline
\end{tabular}

*TVC, Pseudomonas spp., Enterobacteriaceae and LAB are expressed as Log CFU/g. 
decreased till T90 to $0.828-0.863$, values that certainly inhibit microbial growth. As expected, $\mathrm{a}_{\mathrm{w}}$ values were not changed by vacuum storage for 30 days.

\section{Growth potential of Listeria spp. in "Bergamasco" salami}

The trends of Listeria spp. concentration in the inoculated samples are shown in Table 5. As can be seen from the data reported, for batch 1 , in the initial period, a decrease in Listeria spp. inoculated in the product was obtained, with subsequent stabilization. No increase in Listeria spp. loads was observed at any time, considering $\mathrm{T} 0$ or T20 starting values. The same trend was observed in the samples stored under vacuum, in which a further decrease of the concentration was generally detected during the storage at $12^{\circ} \mathrm{C}$ for 30 days (average decrease was $0.32 \mathrm{Log} \mathrm{CFU} / \mathrm{g}$ from $\mathrm{T} 0$ ). The value of $\delta$ calculated for batch 1 was at T90 equal to -1.04

In batch 2 (Table 5), a slight increase of Listeria spp. concentration in inoculated units was observed from T0 to T20 $(+0.25$ Log $\mathrm{CFU} / \mathrm{g}$ ), then a gradual decrease occurred during the rest of the trial $(-0.65$ Log CFU/g at T80). Decreasing concentrations were observed also in vacuum packaged units during the storage at $12^{\circ} \mathrm{C}$ for 30 days, with an average decrease of 0.42 $(+0.11 /-1.53) \mathrm{Log} C F U / g$. The value of $\delta$ found in batch 2 was finally of $-0.59 \mathrm{Log}$ $\mathrm{CFU} / \mathrm{g}$.

In batch 3 , an initial stable trend of Listeria spp. counts, followed by a decrease in the second part of the trial (especially from T50) was detected. As for the other two batches, no increase in Listeria spp. loads was observed at any time, considering both the initial values and the values recorded at T20. As for the other batches, the vac- uum packaging resulted in a decrease in the bacterial loads with an average reduction of $0.34 \mathrm{Log}$ CFU/g (-0.09/-1.73). The value of $\delta$ found in batch 3 was -0.87 .

\section{Discussion}

"Bergamasco" salami showed to be characterized by a very high microflora concentration level, typical for this product, due to the addition of starters cultures to the salami mass. These microorganisms, during the first phases of drying and curing of the product, could represent the potential competitors of Listeria spp., that may be present in raw meat. The mechanisms of action have been extensively studied (competition for nutrients, production of organic acids, bacteriocins, etc.). It is known that the achievement of a "critical" load of lactic bacteria causes a stop of the replication of other bacteria that may be present ("Jameson effect") (Jameson, 1962; Gálvez et al., 2008). In the case of the Bergamasco salami, the growth of LAB rapidly reached a plateau around $8 \mathrm{Log} \mathrm{CFU} / \mathrm{g}$, leading to an acidification of the mass and a substantial stabilization of the product. The $\mathrm{pH}$ of the "Bergamasco" salami followed the expected curves for this type of products, characterized by an acidification, caused by the rapid development of lactic acid bacteria due to the high temperatures applied during drying, while subsequently a gradual increase of the values was observed. Water activity, thanks to the initial drying phase, reached unfavourable values for Listeria spp. growth, and gradually decreased during curing, making the substrate less suitable for its development.

The combination of microbiological and chemical-physical factors that charac- terized the product has never allowed the development of L. innocua inoculated strains; among the factors, the greatest influence was exerted by the water activity, already completely inhibitory starting from T20-T30, combined with the high and constant loads of competing LAB; $\mathrm{pH}$ values acted as a further hurdle to microbial growth, although alone it was not enough to completely inhibit the growth.

Considering growth potential of Listeria spp., the loads measured during the test carried out on three different batches, indicated the absence of a significant growth in the product. The further storage under vacuum of salami, even in thermal abuse, did not determine any development of the inoculated L. innocua strains, resulting in a further decrease of about 0.3-0.4 Log CFU/g.

Considering, for each withdrawal time, the least favourable batch (thus the highest growth potential obtained among the three replicates), it was therefore evident that, both in the samples stored in curing room at a temperature of $14-16^{\circ} \mathrm{C}$ and a humidity of $78-80 \%$ (conditions more permissive than those used during the normal storage of the product), and in the vacuum packaged samples stored at $12^{\circ} \mathrm{C}$, the threshold of +0.5 Log CFU/g, defined by the EURL Lm guidelines for the development of L. monocytogenes was never overcome.

In conclusion, the product tested can be classified, according to the EC Reg. $2073 / 2005$, Annex I, in the category 1.3 as "Ready-to-eat food that is not favourable for growth of L. monocytogenes, other than those intended for infants and for special medical purposes". The Regulation therefore only prescribes the need to ensure that L. monocytogenes loads do not exceed the

Table 5. Median growth potential values of $L$. innocua in inoculated samples maintained in the ageing room or vacuum packaged and maintained at $12^{\circ} \mathrm{C}$ (results reported as difference between T0 values and T20 values in Log CFU/g). In italics are indicated the less favorable data among the three batches.

\begin{tabular}{|c|c|c|c|c|c|c|c|c|c|c|c|}
\hline LogCFU/g & Batch & T0 & $\mathrm{T} 4$ & $\mathrm{~T} 20$ & T30 & $\mathrm{T} 40$ & T50 & $\mathrm{T} 60$ & T70 & $\mathrm{T} 80$ & T90 \\
\hline$\delta \mathrm{T} 0$ & $\begin{array}{l}1 \\
2 \\
3\end{array}$ & $\begin{array}{l}2.52^{*} \\
2.13^{*} \\
2.48^{*}\end{array}$ & $\begin{array}{l}-0.22 \\
+0.25 \\
-0.24\end{array}$ & $\begin{array}{l}-0.26 \\
+0.20 \\
-0.18\end{array}$ & $\begin{array}{l}-0.37 \\
+0.12 \\
-0.11\end{array}$ & $\begin{array}{c}-0.33 \\
+0.06 \\
-0.21\end{array}$ & $\begin{array}{l}-0.36 \\
-0.05 \\
-0.63\end{array}$ & $\begin{array}{l}-0.21 \\
-0.23 \\
-0.33\end{array}$ & $\begin{array}{l}-0.39 \\
-0.23 \\
-0.45\end{array}$ & $\begin{array}{l}-1.04 \\
-0.65 \\
-1.18\end{array}$ & $\begin{array}{l}-1.04 \\
-0.59 \\
-0.87\end{array}$ \\
\hline$\delta \mathrm{T} 20$ & $\begin{array}{l}1 \\
2 \\
3\end{array}$ & $\begin{array}{l}- \\
- \\
-\end{array}$ & $\begin{array}{l}- \\
-\end{array}$ & $\begin{array}{l}2.26^{* *} \\
2.33^{* *} \\
2.30^{* *}\end{array}$ & $\begin{array}{l}-0.11 \\
-0.07 \\
+0.07\end{array}$ & $\begin{array}{l}-0.07 \\
-0.14 \\
-0.03\end{array}$ & $\begin{array}{l}-0.10 \\
-0.25 \\
-0.45\end{array}$ & $\begin{array}{l}+0.05 \\
-0.43 \\
-0.15\end{array}$ & $\begin{array}{l}-0.13 \\
-0.43 \\
-0.28\end{array}$ & $\begin{array}{l}-0.78 \\
-0.85 \\
-1.00\end{array}$ & $\begin{array}{l}-0.78 \\
-0.79 \\
-0.70\end{array}$ \\
\hline & & & & $120+30$ & $730+30$ & $T 40+30$ & $\mathrm{~T} 50+30$ & $760+30$ & $\mathrm{~T} 70+30$ & $\mathrm{~T} 80+30$ & $\mathrm{~T} 90+30$ \\
\hline$\delta \mathrm{T} 0$ & $\begin{array}{l}1 \text { (vac.) } \\
2 \text { (vac.) } \\
3 \text { (vac.) }\end{array}$ & $\begin{array}{l}- \\
- \\
-\end{array}$ & $\begin{array}{l}- \\
- \\
-\end{array}$ & $\begin{array}{l}-0.39 \\
-0.26 \\
-0.66\end{array}$ & $\begin{array}{l}-0.92 \\
-0.15 \\
-0.42\end{array}$ & $\begin{array}{c}-0.36 \\
+0.11 \\
-0.29\end{array}$ & $\begin{array}{l}-0.54 \\
-0.48 \\
-0.52\end{array}$ & $\begin{array}{l}-0.52 \\
-0.73 \\
-1.08\end{array}$ & $\begin{array}{l}-1.34 \\
-0.59 \\
-1.30\end{array}$ & $\begin{array}{l}-0.98 \\
-1.13 \\
-1.08\end{array}$ & $\begin{array}{l}-1.52 \\
-1.53 \\
-1.78\end{array}$ \\
\hline$\delta \mathrm{T} 20$ & $\begin{array}{l}1 \text { (vac.) } \\
2 \text { (vac.) } \\
3 \text { (vac.) }\end{array}$ & $\begin{array}{l}- \\
- \\
-\end{array}$ & $\begin{array}{l}- \\
- \\
-\end{array}$ & $\begin{array}{l}-0.13 \\
-0.45 \\
-0.49\end{array}$ & $\begin{array}{l}-0.66 \\
-0.35 \\
-0.24\end{array}$ & $\begin{array}{l}-0.10 \\
-0.09 \\
-0.11\end{array}$ & $\begin{array}{l}-0.28 \\
-0.68 \\
-0.35\end{array}$ & $\begin{array}{l}-0.26 \\
-0.93 \\
-0.90\end{array}$ & $\begin{array}{l}-1.09 \\
-0.79 \\
-1.12\end{array}$ & $\begin{array}{l}-0.72 \\
-1.33 \\
-0.90\end{array}$ & $\begin{array}{l}-1.26 \\
-1.73 \\
-1.60\end{array}$ \\
\hline
\end{tabular}

${ }^{*}$ Listeria spp. concentration at T0; ${ }^{* *}$ Listeria spp. concentration at T20; vac. = vacuum. 
level of $100 \mathrm{CFU} / \mathrm{g}$ during the commercial life, as the absence of the pathogen in the product before leaving the production plant, is not mandatory. Finally, it is important to specify that, any eventual modification of the recipe or of the production process of "Bergamasco" salami needs to be carefully evaluated, in order to keep unfavourable conditions for the growth of L. monocytogenes and thus to ensure the safety of this traditional meat product.

\section{References}

ANSES, 2013. Development of a set of Listeria monocytogenes strains for conducting challenge tests. Version 0 : 20/12/2013

ANSES, 2014. EURL Lm technical guidance document for conducting shelf-life studies on Listeria monocytogenes in ready-to-eat foods. Version 3; 6 June 2014.

Barbuti S, Ghisi M, Campanini M, 1989. Listeria in prodotti carnei: isolamento, incidenza e caratteristiche di sviluppo. Industria Conserve 64:221-4.

Bunčić S, Paunovic L, Radisic D, 1991. The fate of Listeria monocytogenes in fermented sausages and in vacuum-packaged frankfurters. J Food Protect 54:413-7.

Cantoni C, 1991. Controllo delle listerie negli stabilimenti della carne. Industrie Alimentari 30:271-3.

Cantoni C, Valenti M, Comi G, 1988. Listeria in formaggi e salumi. Industrie Alimentari 27:859-61.

De Cesare A, Mioni R, Manfreda G, 2007. Prevalence of Listeria monocytogenes in fresh and fermented Italian sausages and ribotyping of contaminating strains. Int J Food Microbiol 120:124-30.

Drosinos EH, Mataragas M, VeskovicMoracanin S, Gasparik-Reichardt J, Hadziosmanovic M, Alagic D, 2006. Quantifying non-thermal inactivation of Listeria monocytogenes in European fermented sausages using bacteriocinogenic lactic acid bacteria or their bacte- riocins: A case study for risk assessment. J Food Protect 69:2648-63.

EC (European Commission), 2005. European Commission Regulation No. 2073/2005 of 15 November 2005 on microbiological criteria for food-stuffs. Official Journal of the European Union, L338, 22/12/2005.

EFSA, ECDC (European Food Safety Authority and European Centre for Disease Prevention and Control), 2017. The European Union Summary Report on Trends and Sources of Zoonoses, Zoonotic Agents and Food-borne Outbreaks in 2016. EFSA J 15:5077.

FAO-WHO (Food and Agriculture Organization-World Health Organization), 2001. Joint FAO/WHO expert consultation on risk assessment of microbiological hazards in food. Risk characterization of Salmonella spp. in eggs and broiler chickens and Listeria monocyotgenes in ready-to-eat foods. FAO Food and Nutrition Paper $n^{\circ} 72$, FAO, Rome, Italy, pp. 26-27.

Farber JM, Peterkin P, 1991. Listeria monocytogenes, a food-borne pathogen. Microbiol Mol Biol Rev 55:476-511.

Gálvez A, López RL, Abriouel H, Valdivia E, Omar NB, 2008. Application of bacteriocins in the control of foodborne pathogenic and spoilage bacteria. Crit Rev Biotechnol 54:125-52.

ISO (International Organization for Standardisation), 1998. Microbiology of food and animal feeding stuffs Horizontal method for the enumeration of mesophilic lactic acid bacteria Colony-count technique at 30 degrees C. ISO 15214:1998.

ISO (International Organization for Standardisation), 2004. Microbiology of food and animal feeding stuffs Horizontal methods for the detection and enumeration of Enterobacteriaceae - Part 2: Colony-count method. ISO 21528-2:2017.

ISO (International Organization for Standardisation), 2010. Meat and meat products - Enumeration of presumptive Pseudomonas spp. ISO 13720:2010.
ISO (International Organization for Standardisation), 2013. Microbiology of the food chain - Horizontal method for the enumeration of microorganisms - Part 2: Colony count at 30 degrees C by the surface plating technique. ISO 4833-2:2013.

Jackson KA, Iwamoto M, Swerdlow D, 2010. Pregnancy-associated listeriosis. Epidemiol Infect 138;1503-9.

Jameson JE, 1962. A discussion of the dynamics of Salmonella enrichment. J Hygiene 60:193-207.

Martin B, Garriga M, Aymerich T, 2011. Prevalence of Salmonella spp. and Listeria monocytogenes at small-scale Spanish factories producing traditional fermented sausages. J Food Protect 74:812-5.

Mataragas M, Bellio A, Rovetto F, Astegiano S, Decastelli L, Cocolin L, 2015. Risk-based control of food-borne pathogens Listeria monocytogenes and Salmonella enterica in the Italian fermented sausages Cacciatore and Felino. Meat Sci 103:39-45.

Meloni D, 2015. Presence of Listeria monocytogenes in Mediterranean-Style Dry Fermented Sausages. Foods 4:34-50.

Silk BJ, Date KA, Jackson KA, Pouillot R, Holt KG, Graves LM, Ong KL, Hurd S, Meyer R, Marcus R, Shiferaw B, Norton DM, Medus C, Zansky SM, Cronquist $\mathrm{AB}$, Henao $\mathrm{OL}$, Jones TF, Vugia DJ, Farley MM, Mahon BE, 2012. Invasive listeriosis in the Foodborne Diseases Active Surveillance Network (FoodNet), 20042009: further targeted prevention needed for higher-risk groups. Clin Infect Dis 54:S396-404.

Thévenot D, Delignette-Muller ML, Christieans S, Vernozy-Rozand C, 2005. Prevalence of Listeria monocytogenes in 13 dried sausage processing plants and their products. Int J Food Microbiol 102:85-94.

Tompkin RB, 2002. Control of Listeria monocytogenes in the food processing environment. J Food Protect 65:709-25. 